\title{
Seabirds as indicators of marine food supplies: Cairns revisited
}

\author{
John F. Piatt ${ }^{1, *}$, Ann M. A. Harding ${ }^{1,2}$, Michael Shultz ${ }^{1}$, Suzann G. Speckman ${ }^{3}$, \\ Thomas I. van Pelt ${ }^{1}$, Gary S. Drew ${ }^{1}$, Arthur B. Kettle ${ }^{4}$ \\ ${ }^{1}$ US Geological Service Alaska Science Center, 1011 E. Tudor Rd., Anchorage, Alaska 99503, USA \\ ${ }^{2}$ Alaska Pacific University, Environmental Science Department, 4101 University Dr., Anchorage, Alaska 99508, USA \\ ${ }^{3}$ School of Aquatic and Fishery Sciences, University of Washington, 1122 NE Boat St., Seattle, Washington 98105, USA \\ ${ }^{4}$ Alaska Maritime National Wildlife Refuge, US Fish and Wildlife Service, 2355 Kachemak Bay Dr., Homer, Alaska 99603, USA
}

\begin{abstract}
In his seminal paper about using seabirds as indicators of marine food supplies, Cairns (1987, Biol Oceanogr 5:261-271) predicted that (1) parameters of seabird biology and behavior would vary in curvilinear fashion with changes in food supply, (2) the threshold of prey density over which birds responded would be different for each parameter, and (3) different seabird species would respond differently to variation in food availability depending on foraging behavior and ability to adjust time budgets. We tested these predictions using data collected at colonies of common murre Uria aalge and black-legged kittiwake Rissa tridactyla in Cook Inlet, Alaska. (1) Of 22 seabird responses fitted with linear and non-linear functions, 16 responses exhibited significant curvilinear shapes, and Akaike's information criterion (AIC) analysis indicated that curvilinear functions provided the best-fitting model for 12 of those. (2) However, there were few differences among parameters in their threshold to prey density, presumably because most responses ultimately depend upon a single threshold for prey acquisition at sea. (3) There were similarities and some differences in how species responded to variability in prey density. Both murres and kittiwakes minimized variability $(\mathrm{CV}<15 \%)$ in their own body condition and growth of chicks in the face of high annual variability $(C V=69 \%)$ in local prey density. Whereas kittiwake breeding success $\left(\mathrm{CV}=63 \%, \mathrm{r}^{2}=0.89\right)$ reflected prey variability, murre breeding success did not $\left(\mathrm{CV}=29 \%, \mathrm{r}^{2}<0.00\right)$. It appears that murres were able to buffer breeding success by reallocating discretionary 'loafing' time to foraging effort in response $\left(\mathrm{r}^{2}=0.64\right)$ to declining prey density. Kittiwakes had little or no discretionary time, so fledging success was a more direct function of local prey density. Implications of these results for using 'seabirds as indicators' are discussed.
\end{abstract}

KEY WORDS: Ecological indicators · Seabirds · Food availability · Threshold · Functional response · Predator-prey dynamics

\section{INTRODUCTION}

Annual global fisheries landings are currently 80 million $t$, and seabirds worldwide consume similar quantities of fish (Brooke 2004). With such strong dependence on shared resources, it is not surprising that we look to seabirds for additional insights into the status of fish stocks and the health of marine ecosystems (Cairns 1987, Montevecchi 1993, Furness \& Camphuysen 1997). For this purpose, seabirds offer many advantages. They are highly visible at sea, and large numbers gather annually to reproduce at colonies where it is often possible to study the biology of several species in great detail every year.

However, care must be taken when interpreting seabird data as a proxy for fish abundance (Furness \& Camphuysen 1997) because different components of seabird biology may respond differently to prey fluctuations, and responses also vary among species. Twenty years ago, Cairns (1987) published a seminal paper in 
which he sought to clarify relationships between seabirds and their food supplies. He predicted that many responses of seabirds to fluctuations in prey abundance would be non-linear, and further, that different parameters such as growth rates, breeding success or survival would respond over different ranges of prey density (around thresholds, Fig. 1). Finally, he predicted that different seabird species would respond differently depending on their diet and ability to adjust time budgets. Cairns had 2 main objectives in his analysis: (1) to 'develop an integrated system of parameter measurement that indicates food availability over the full spectrum of feeding conditions' and (2) 'to stimulate rigorous tests of the proposed relationships' (p. 262).

Since Cairns' paper was published, there have been a few coordinated studies of seabird biology in relation to prey abundance (e.g. Monaghan et al. 1989, 1994, Hamer et al. 1991, 1993, Uttley et al. 1994, Reid et al. 2005, Frederiksen et al. 2006), but none were designed to explicitly test Cairns' predictions. In order to flesh out functional response curves, one needs data collected over a wide range of prey densities (Piatt 1990). For most seabirds and parameters, this has simply not been done (Furness \& Camphuysen 1997), owing largely to the cost and technical difficulties of measuring forage fish abundance over the times and spaces relevant to seabird colonies.

Following the 1989 'Exxon Valdez' oil spill in Alaska, understanding how seabirds had responded to concurrent large-scale fluctuations in prey abundance was paramount to understanding the effects of the spill itself (Anderson \& Piatt 1999). We therefore used Cairns' hypotheses as a framework for examining relationships between seabirds and their prey in the Gulf of Alaska (Piatt \& Harding 2007). Our study constituted a natural experiment to resolve predator-prey functional relationships by studying 3 closely situated colonies with markedly different prey fields over a 5 yr period. These colonies differed in other respects besides local prey density (e.g, prey distribution, colony size), but the signal from spatio-temporal variability in prey abundance overwhelmed other sources of variability, permitting us to resolve many functional predator-prey relationships (Speckman 2004, Piatt \& Harding 2007, Harding et al. 2007).

In the present paper, we use results of our natural experiment to test Cairns' (1987) 3 predictions about the form and variation of seabird responses to changes in local prey density. We plot data collected on a dozen different parameters of breeding and behavior from common murres Uria aalge and black-legged kittiwakes Rissa tridactyla against prey density estimated from hydro-acoustic surveys. We analyze the fit of parameter responses to various linear and non-linear
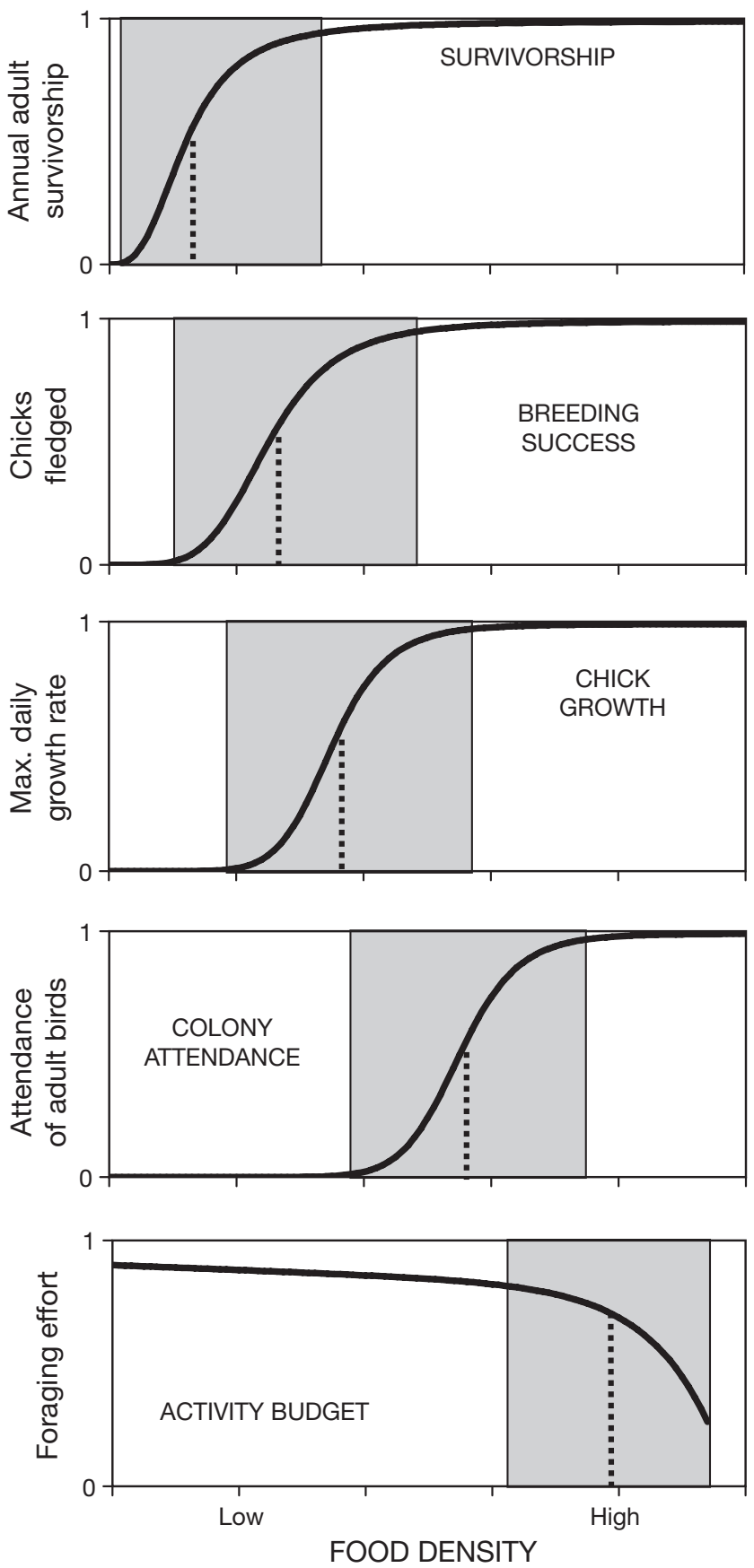

Fig. 1. Cairns' predicted relationships between population and behavioral parameters of seabirds and their food supply. Dashed vertical lines indicate approximate threshold or halfway point in parameter response to change in prey density. Modified from Cairns (1987)

models using regression and AIC analyses, compare thresholds among parameters, and then compare responses and thresholds between murres and kittiwakes. Implications of these results for using seabirds as indicators are discussed within the framework of Cairns' original hypothesis. 


\section{MATERIALS AND METHODS}

Study sites and rationale. This study was conducted during 5 yr (1995 to 1999) at 3 seabird colonies in Lower Cook Inlet, Alaska (Fig. 2), providing us with 15 colony-years of data for many parameters that we investigated (less for some parameters when it was impossible to collect data, e.g. feeding or growth rates when no chicks were produced). The colonies are separated from each other by about $100 \mathrm{~km}$ and are in oceanographically distinct habitats (Abookire \& Piatt 2005, Speckman et al. 2005). We confirmed that there were order-of-magnitude differences in forage fish densities among the 3 areas by sampling near shore with beach seines (Robards et al. 1999) and by sampling offshore with mid-water trawls and hydroacoustic surveys (Abookire \& Piatt 2005, Speckman et al. 2005). Four species comprised $99 \%$ of the catches in all areas: sand lance Ammodytes hexapterus (71\%), herring Clupea harengus (17.7\%), juvenile walleye pollock Theragra chalcogramma $(8.8 \%)$, and capelin Mallotus villosus (1.7\%), and these fish were also the

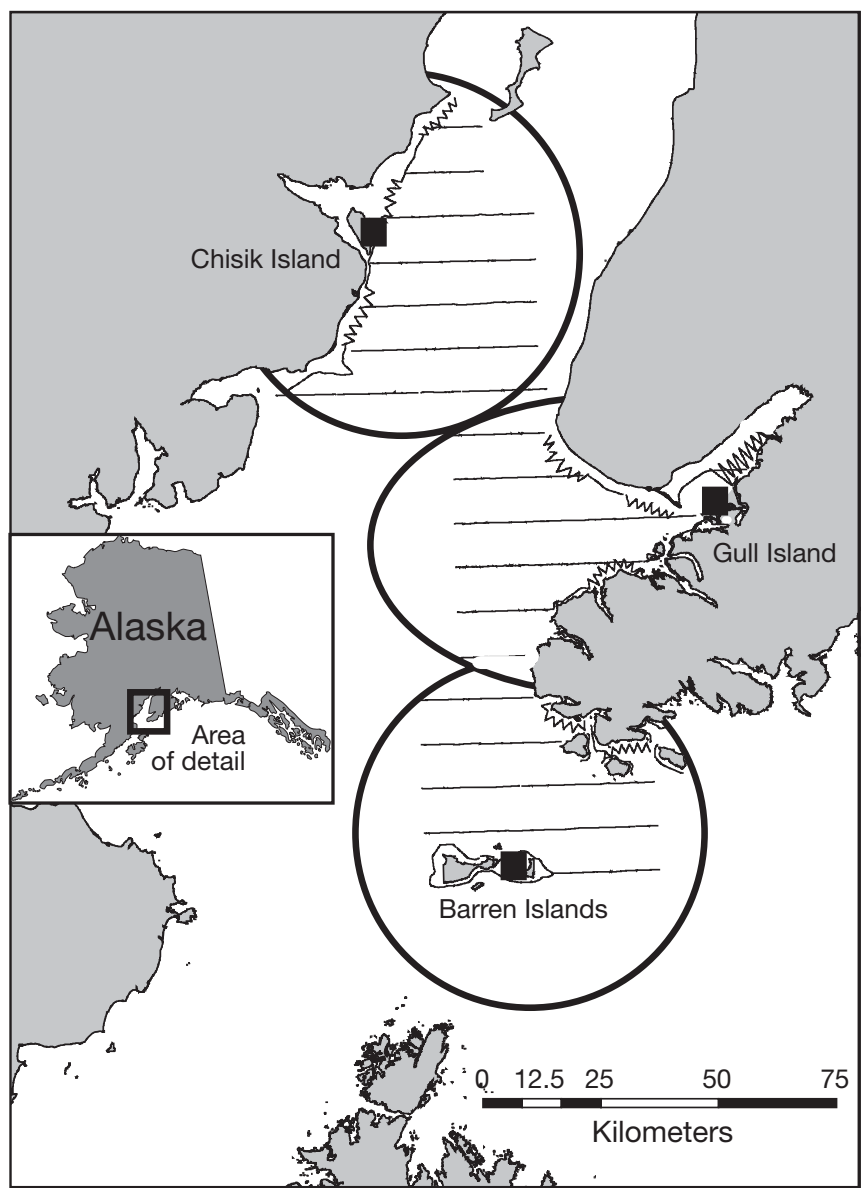

Fig. 2. Study areas in lower Cook Inlet, Alaska. Illustrated are tracks of hydro-acoustic and bird surveys conducted within about a $50 \mathrm{~km}$ radius (circles) of each colony overwhelming choice of prey consumed by seabirds at all colonies (Kitaysky et al. 1999, Harding et al. 2002, Jodice et al. 2006, J. F. Piatt unpubl. data).

Local prey density. We measured local fish densities around each of 3 seabird colonies by conducting hydro-acoustic surveys on a grid of transects arranged in most years as shown in Fig. 2, within a $50 \mathrm{~km}$ radius of each site (Speckman et al. 2005, Harding et al. 2007). Transects around the Barren Islands were concentrated in the NE quadrant, known as foraging grounds for the majority of murres Uria aalge and kittiwakes Rissa tridactyla from the Barrens (J. F. Piatt unpubl. data). About 1100 linear km were surveyed in all areas combined each year (except $820 \mathrm{~km}$ in 1995) (Speckman 2004). Hydro-acoustic surveys were conducted during a $3 \mathrm{wk}$ period in each year $(1995,10$ to 23 August; 1996, 14 to 31 July; 1997, 19 July to 8 August; 1998, 21 July to 12 August; 1999, 25 July to 16 August), usually encompassing periods of late incubation and early chick rearing for common murres (overall colony/year mean date of hatch was 10 August; J. F. Piatt \& A. B. Kettle unpubl. data).

Hydro-acoustic data were collected with a single beam $120 \mathrm{kHz}$ BioSonics DT4000 system with a $6^{\circ}$ beam angle. Before each cruise the acoustic system was calibrated using a tungsten carbide sphere. To identify acoustic signals and measure the size of individual fish, we conducted 163 mid-water trawls (Abookire \& Piatt 2005). Acoustic data were analyzed using SonarData Echoview software (Ver. 2.1) and integrated with a minimum threshold of $-70 \mathrm{~dB}$ to obtain relative measures of acoustic biomass $\left(S_{\mathrm{A}}\right)$. These were converted to absolute estimates of fish density (fish $\mathrm{m}^{-3}$ ) by dividing $S_{\mathrm{A}}$ by $\sigma$ (backscattering cross-sectional area of single prey) for species with the following known target strengths (TS): walleye pollock TS $=21.1 \log (L)-70.5$, herring TS $=202.0 \log (L)-67.6$, capelin TS $=$ 28.4Log $(L)-81.8$, sand lance TS $=20.0 \log (L)-80$, and $\operatorname{cod}$ TS $=20.0 \log (L)-65$; which accounted for $99.2 \%$ of all fish caught (see Speckman et al. 2005 for TS sources). The proportion of catch, expressed as catch per unit effort, standardized to the number captured per $\mathrm{km}$ trawled, was used to convert acoustic backscatter to species-specific fish density $\left(\mathrm{g} \mathrm{m}^{-3}\right)$. Geometric mean acoustic densities were calculated from transformed data as the mean $(\log x+1)$ values, and then transformed back to original density units.

Seabird parameters. Density of seabirds at sea was determined from strip transects conducted simultaneously with hydro-acoustic surveys (above). All species of seabirds observed within $150 \mathrm{~m}$ on either side of the vessel were counted using protocols described by Gould \& Forsell (1989). Average densities on transects were calculated for each species in each area (Fig. 2) and year (except 1995, Speckman 2004). 
Behavioral activity budgets were determined from all-day observations of 8 to 12 nest-sites of adult murres and kittiwakes at each colony during the incubation and chick-rearing period in each of the 15 colony-years (see Harding et al. 2007 for more details). During observations, the time was recorded for each adult arrival, delivery of prey to chicks (chick-rearing period), exchange of incubation or brooding duty, and adult departure. On Gull (1996 to 1997) and Barren (1997 to 1999) islands, murre observations were recorded by video from first to last light and analyzed later (Zador \& Piatt 1999). In most instances, we observed murres and kittiwakes on 3 or more observation-days during incubation and chick-rearing of each year.

From these observations, we calculated average annual rates of nest-site attendance by 1 and 2 adults, chick-feeding rates, and foraging-trip durations. Nest attendance was measured in bird-minutes per nest per h (e.g. a nest with 1 bird attending for a full hour and its mate attending for half of the hour has 90 birdminutes that hour). Adult provisioning frequency was measured in feedings per nest per $h$. The mass and species composition of kittiwake chick meals was measured and used to estimate total energy delivered to chicks daily (see Jodice et al. 2006). Analysis of variance indicated that neither nest-site nor observationday contributed significantly to variability in behavioral parameters in a given year, and we therefore used nest-site as the sample unit. Sample sizes ranged from 20 to 35 nest-site-days watched per island-year (except at Chisik, where kittiwakes failed in all years but 2).

Measures of murre and kittiwake breeding biology were derived from data recorded during regular ( $3 \mathrm{~d}$ average) observations of 20 to 30 nest-sites on 7 to 10 plots scattered around the colony (e.g. Uttley et al. 1994, Suryan \& Irons 2001). For kittiwakes, we estimated laying success, clutch size, hatching success, fledging success, brood size at fledging, chick age, and reproductive success. Chicks were considered fledged at $32 \mathrm{~d}$ of age. For murres, we estimated hatching success, fledging success, chick age, and reproductive success. Chicks were considered to have fledged if they disappeared from the nest-site $>15 \mathrm{~d}$ after hatching (minimum fledging age, Gaston \& Jones 1998).

We captured or collected both adult and chick murres and kittiwakes at their colonies to measure body size and body mass and to calculate growth rates and fledging condition of chicks. Adult body mass of both murres and kittiwakes was obtained from 2 sources: (1) adults captured at the colony throughout breeding to assess body condition (1997 to 1999) and (2) adults shot near colonies for diet studies (1995 and 1996). Only birds measured during late incubation through early chick-rearing were used to calculate an annual index of body condition, and a minimum of 10 to 35 birds was included in each colony-year estimate. For murres, there was no difference in mean size of birds among colonies (ANOVA, $F_{2,12}=0.522$, $p=0.61$ ), so here we simply present data on body mass. Because kittiwakes are sexually dimorphic and samples were unevenly composed of both sexes, we used the ratio of body mass to wing length as an index of body condition (Benson et al. 2003).

Kittiwake chick growth rates were calculated from a plot of mass versus age during the linear phase of growth, defined as falling between 6 and $22 \mathrm{~d}$ of age or between 60 and $300 \mathrm{~g}$ of mass (Benson et al. 2003). We tried to measure a total of 30 to 45 kittiwake chicks for growth in each colony and year, but in 6 of 15 possible colony-years fewer chicks were available for measuring and sample sizes ranged from 2 to 16 birds. It was not possible to repeatedly capture and weigh murre chicks without major disturbance, so murre chicks were captured only once immediately after fledging from nests at dusk. Samples were obtained throughout the fledging period (average of 65 chicks per colony during 10 colony-years). An index of fledgling body mass was calculated by dividing mass by wing length, and this serves as a proxy for chick growth rate.

Analysis. Parameters of murre and kittiwake biology were plotted against forage fish biomass to examine the form of each response. Because we were testing Cairns' hypothesis that responses should be non-linear and thresholds should differ among parameters and species, we used least-squares estimation to fit linear and several non-linear models (Reid et al. 2005). Thresholds were estimated from the inflection mid-points of sigmoidal and step functions and as the $50 \%$ mid-point of exponential curves (Fig. 1). The potential strength of relationships between forage fish abundance and response parameters was assessed from the $\mathrm{r}^{2}$ of each regression, and statistical significance was determined from the corresponding $F$-statistic (Reid et al. 2005). We assumed statistical significance at the $\mathrm{p}<0.05$ level.

Data were fit to 1 linear and 4 different non-linear models, including hyperbolic, sigmoidal (logistic), step, and exponential decay functions. These were the forms predicted by Cairns (1987) and might be reasonably expected from foraging seabirds (Piatt 1990). They also correspond to the Type I (linear), Type II (hyperbolic), and Type III (sigmoid/step) predator-prey functional relationships described by Holling (1959) and commonly observed in vertebrate predators (Murdoch \& Oaten 1975).

The following 2-parameter function was used to fit hyperbolic curves:

$$
f=(a \times x) /(b+x)
$$

where $a$ is the maximum value, $b$ is the dissociation constant, and $f$ starts at zero and rises to $a$. 
The following 4-parameter logistic function was used to fit sigmoidal curves:

$$
f=(a-d) /\left[1+(x / c)^{b}\right]+d
$$

where $a$ is the asymptotic maximum, $b$ is the slope parameter $(b<0$ gives slope $>0), c$ is the value at inflexion point and $d$ is the asymptotic minimum.

The step function represents a simplification of the sigmoidal curve. A simple box model (Piatt \& Methven 1992) of a step function was used to locate thresholds in response plots and estimate goodness of fit $\left(\mathrm{r}^{2}\right)$. The model used was:

$$
\begin{aligned}
& f=k_{1} D \text { if } D>D_{\mathrm{T}} \\
& f=k_{2} D \text { if } D<\mathrm{D}_{\mathrm{T}}
\end{aligned}
$$

where $f$ is the bird parameter value, $D$ is the forage fish density, $D_{\mathrm{T}}$ is the test threshold for forage fish density, and $k_{1}$ and $k_{2}$ are mean parameter values above and below the test threshold $D_{\mathrm{T}}$. The best fit (highest $\mathrm{r}^{2}$ ) to the step function occurs at the inflection point (Piatt 1990).

A non-linear exponential decay function was used to model negative, declining responses to prey density using the following:

$$
f=a \times \exp (-b \times x)
$$

where $a$ is amplitude and $b$ is the rate constant.

Whereas regression is useful for determining the strength of possible functional relationships and for identifying thresholds, it was more appropriate to use $\mathrm{AIC}$, adjusted for finite sample size $\left(\mathrm{AIC}_{\mathrm{c}}\right.$ Burnham \& Anderson 2002) to identify the best-fitting model among several possible alternatives. For positive relationships between seabirds and prey, we compared 5 possible functional models: (1) null-no relationship whatsoever between seabird parameters and food density (slope equals zero), (2) linear (positive slope), (3) hyperbolic, (4) sigmoidal, and (5) a step function. For negative relationships, we compared 3 likely or possible models: (1) null (as above), (2) linear (negative slope), and (3) a negative exponential function.

Each model was statistically represented with a leastsquares regression model in which the error sums of squares, sample size, and number of estimated parameters all influenced the $\mathrm{AIC}_{\mathrm{C}}$ calculation (Burnham \& Anderson 2002). The model with the lowest $\mathrm{AIC}_{\mathrm{c}}$ was assumed to best represent the data. Models in which the difference in $\mathrm{AIC}_{\mathrm{c}}$ from the minimum value $\left(\Delta \mathrm{AIC}_{\mathrm{c}}\right)$ is $<2$ are considered plausible alternative models. For each model, we also calculated an $\mathrm{AIC}_{\mathrm{c}}$ weight $(w)$ that reflects the relative likelihood of that model being the best-fitting model among those considered, and in which all $\mathrm{AIC}_{\mathrm{c}}$ weights within an analysis sum to 1 (Burnham \& Anderson 2002).

\section{RESULTS}

\section{Form of responses}

For common murres Uria aalge, no linear relationships were observed among the 10 parameters investigated (Fig. 3, Table 1). Most (8/10) responses to prey density could be fit significantly with sigmoidal or step functions, 1 response was fit significantly with an exponential decay function, and 2 responses exhibited no significant relationship with prey density. $\mathrm{AIC}_{\mathrm{C}}$ analysis confirmed that non-linear models were best among the choices we examined (Table 2) and suggested that 6 of 10 responses were best fit by step, hyperbolic, or exponential functions. $\mathrm{AIC}_{\mathrm{c}}$ analysis penalizes models with more equation parameters and small sample sizes, and so $\Delta \mathrm{AIC}_{\mathrm{c}}$ values and likelihood weights (Table 2) should be considered for alternate models (Burnham \& Anderson 2002). The weight of evidence strongly supports null models for body condition, fledging success, and breeding success, and nonlinear models for fledgling body condition and attendance during incubation and chick-rearing. Other responses were more ambiguous and could be fit reasonably well by 2 or 3 competing models (Table 2).

These results indicate that for murres, relations between reproductive parameters (hatching, fledging, and breeding success) and food supply were marginal at best. Adult body condition was most independent of food supply, while chick condition at fledging exhibited a strong non-linear relation to food and growth was restricted at low levels of prey density. Foraging trip duration increased in an exponential fashion with decreasing prey density. While the chick-feeding rate was weakly related to prey density, other measures of foraging activity such as density at sea (aggregative response) and discretionary attendance at the nest site during incubation and chick-rearing (time that can be allocated instead to foraging) were strong non-linear functions of prey density.

As for murres, no linear relationships were observed among 12 parameters investigated for black-legged kittiwakes Rissa tridactyla (Fig. 4, Table 1). Most (8/12) responses to prey density could be fit significantly with sigmoidal or step functions, 1 response was fit significantly with an exponential decay function, and 4 responses exhibited no significant relationship with prey density. $\mathrm{AIC}_{\mathrm{c}}$ analysis confirmed that non-linear models were best among the choices we examined (Table 2), and suggested that 6 of 12 responses were best fit by step, hyperbolic, or exponential functions. The weight of evidence (1) strongly supports null models for attendance, body condition, and clutch size and (2) strongly supports non-linear models for chick growth rate, fledging success, and breeding success. 


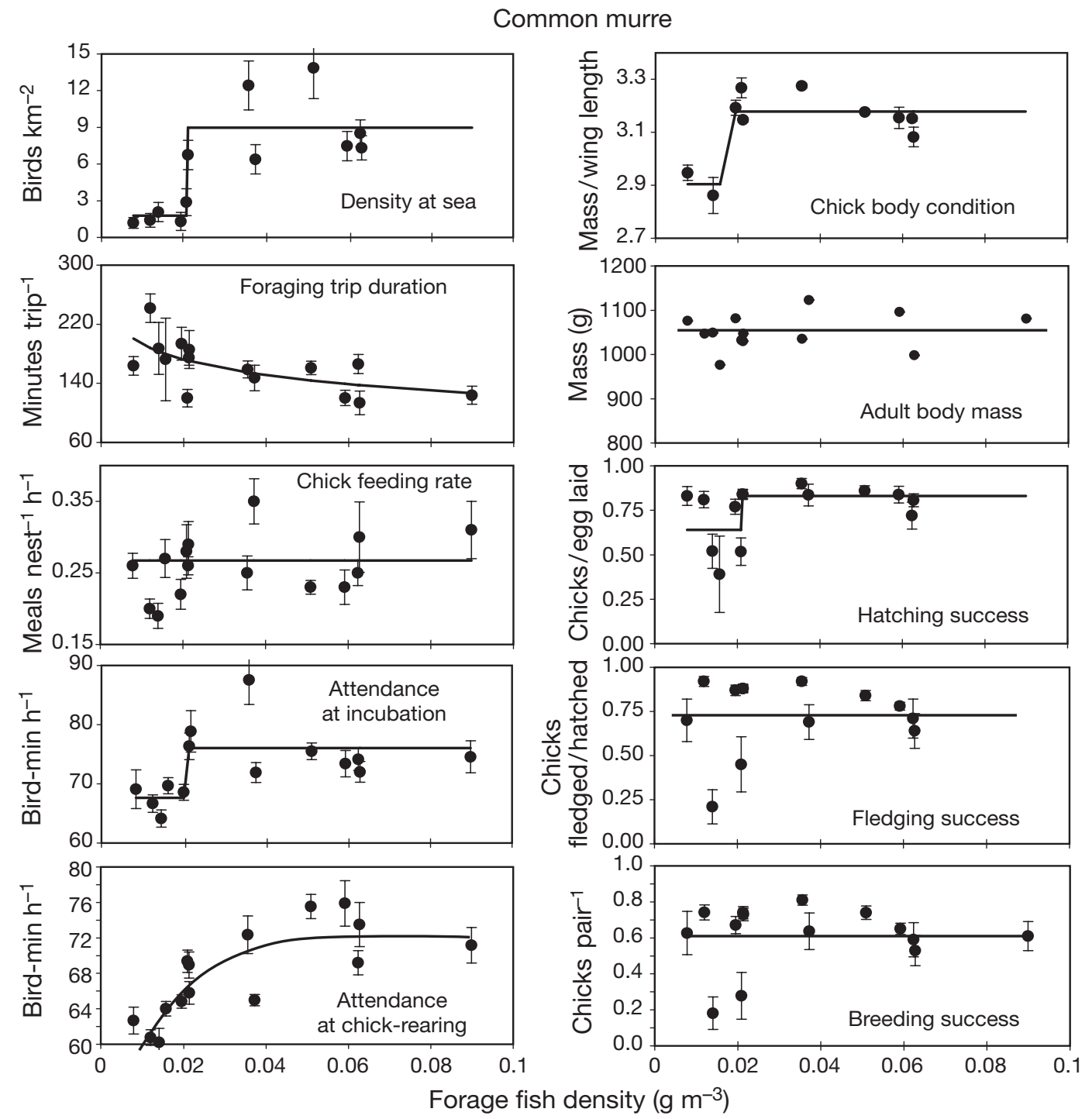

Fig. 3. Uria aalge. Response of different parameters of murre biology or behavior to variation in prey density. Graphs include predicted form (solid line) of relationship from the best-fitting model function (null, linear, hyperbolic, sigmoidal, step, or exponential decay) as determined by using Akaike's information criterion adjusted for sample size $\left(\mathrm{AIC}_{\mathrm{c}}\right)$ analysis

Other parameter responses were more ambiguous, and could be fit reasonably well by 2 or 3 competing models (Table 2), but tended towards either null or linear fits (laying and hatching success, chick feeding rate), or non-linear fits (density at sea, foraging trip duration, brood size).

These results indicate that, in contrast with murres, reproductive parameters for kittiwakes such as fledging and breeding success were strongly related to fluctuations in prey density. Other reproductive parameters such as clutch size, laying success, and hatching success were essentially independent of food supply. Also, in contrast to murres, the discretionary attendance of paired adults at the nest site during chickrearing did not vary with food supply. As for murres, kittiwake chick condition was markedly reduced at low prey densities and adult body condition remained remarkably constant over a wide range of prey densities.

The average prey density threshold for all parameters in murres that exhibited significant relationships with prey density ( $\mathrm{n}=8$; Table 1 ) was $0.022 \pm$ $0.00033 \mathrm{~g} \mathrm{~m}^{-3}$ and in kittiwakes $(\mathrm{n}=8)$ was $0.021 \pm$ $0.00028 \mathrm{~g} \mathrm{~m}^{-3}$. A 2-way ANOVA indicated no significant difference in thresholds among species $(F=3.06$, $\mathrm{p}=0.11$, df $=1,15)$, but a significant difference in thresholds among different types of parameters (see Table 1; $F=44.6, \mathrm{p}<0.001, \mathrm{df}=4,15)$. This was entirely due to the higher threshold values estimated for foraging trip durations, which differed significantly from all other types of parameters (Tukey test; Act $>$ Gro, Att, $\mathrm{Br}$, and For, $\mathrm{p}<0.05$; see Table 1). 
Table 1. Rissa tridactyla, Uria aalge. Functional relationships between different measures of seabird biology or behavior and prey density, and variability in those measures among colony-years. $\mathrm{n}=$ number of colony-years of data. Types of parameters: Att $=$ colony attendance; Gro = body condition or growth; $\mathrm{Br}=$ breeding success; Act $=$ activity budget; For $=$ foraging behavior. Relationships were modeled as null, linear, hyperbolic (hyper), sigmoidal (sigm), step, or exponential (exp) functions. w: Akaike weight; ns: not significant. Variability ranked as low $(\mathrm{CV}<20 \%)$, medium $(20 \%<\mathrm{CV}<40 \%)$, and high $(\mathrm{CV}>40 \%)$, where $\mathrm{CV}$ is the coefficient of variation

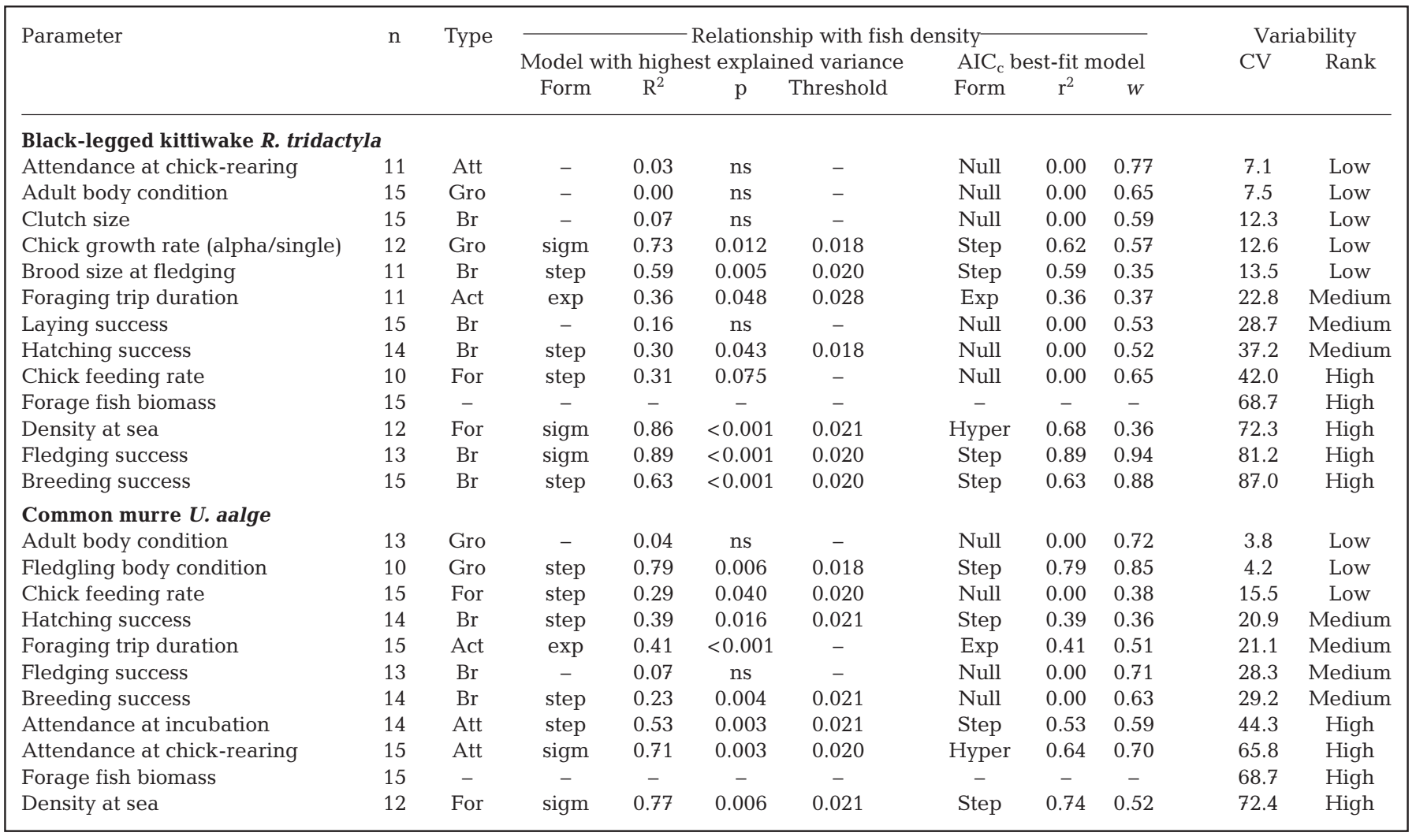

\section{Difference in responses among species}

In addition to assessing the form of functional relations (above), we examined the range in variability of seabird responses (Table 1), as measured by the coefficient of variation $(\mathrm{CV})$.

Forage fish biomass varied about 12-fold among colony-years, with a CV of $79 \%$ (Table 1, Fig. 5). In some respects, murres and kittiwakes responded in the same way to this variation in prey density. Both species exhibited similar levels of variability in density of foraging aggregations at sea (up to 20 -fold, $C V=72 \%$ for both species), which also reflected the variability in forage fish biomass. Despite this large variability in prey biomass, both species exhibited minimal variability in adult body condition or chick growth $(<2$-fold, $\mathrm{CV}<15 \%$ ) and only moderate variability in foragingtrip duration (ca. 2-fold, CV $=20$ to $25 \%$ ).

Murres and kittiwakes differed dramatically in other respects. Whereas murres maintained low variability in chick-feeding rates $(<2$-fold, $\mathrm{CV}=15 \%)$ and moderate levels of variability in hatching, fledging, and breeding success (up to 5-fold, CV $=21$ to $29 \%$ ), kitti- wakes exhibited much higher levels of variation in chick-feeding rate (up to 5 -fold, $\mathrm{CV}=42 \%$ ) and in hatching, fledging, and breeding success (up to 36fold, $\mathrm{CV}=37$ to $87 \%$ ). Also in contrast, kittiwakes exhibited little variation in discretionary attendance of adults at nest-sites ( $<2$-fold, CV $<10 \%$ ), whereas this was the most variable parameter in murres (up to 30 -fold, CV $=65$ to $69 \%$ ).

\section{DISCUSSION}

\section{Non-linearity of response}

Cairns' (1987) first prediction was upheld: where there was a significant functional relationship with prey density, it was non-linear for parameters such as aggregation at sea, colony attendance, foraging trip duration, chick growth brood size, fledging success, and breeding success. A few studies have demonstrated similar results, albeit with fewer parameters. For example, breeding success in several seabird species has been shown to be a curvilinear function of food 
Table 2. Rissa tridactyla, Uria aalge. Identification of best-fit models using Akaike's information criterion, adjusted for finite sample size. Possible models included linear, hyperbolic (hyper), sigmoidal (sigm), step and negative exponential (exp) functions. The best-fitting model is indicated by $\Delta \mathrm{AIC}_{\mathrm{C}}=0$, but all models with $\Delta \mathrm{AIC}_{\mathrm{C}}<2$ (in bold) and high $\mathrm{AIC}_{\mathrm{C}}$ weights relative to other models have substantial support and offer plausible alternative models of functional relationships

\begin{tabular}{|c|c|c|c|c|c|c|c|c|c|c|c|c|c|}
\hline \multirow[t]{2}{*}{ Measurement } & \multirow[t]{2}{*}{$\mathrm{n}$} & \multicolumn{7}{|c|}{$\mathrm{AIC}_{\mathrm{c}}$ weights $(w)$} & \multicolumn{5}{|c|}{$\triangle \mathrm{AICc}$} \\
\hline & & Null & Linear & Hyper & Sigm & Step & Exp & Null & Linear & Hyper & Sigm & Step & Exp \\
\hline \multicolumn{14}{|c|}{ Black-legged kittiwake $R$. tridactyla } \\
\hline Attendance at chick-rearing & 11 & 0.77 & 0.11 & 0.11 & 0.00 & 0.01 & - & 0.00 & 3.86 & 3.87 & 16.03 & 8.71 & - \\
\hline Adult body condition & 15 & 0.65 & 0.18 & 0.14 & 0.00 & 0.02 & - & 0.00 & 2.57 & 3.06 & 11.67 & 6.88 & - \\
\hline Clutch size & 15 & 0.59 & 0.21 & 0.14 & 0.01 & 0.06 & - & 0.00 & 2.05 & 2.92 & 9.13 & 4.65 & - \\
\hline Chick growth rate (alpha/single) & 12 & 0.12 & 0.02 & 0.09 & 0.20 & 0.57 & - & 3.05 & 6.44 & 3.69 & 2.11 & 0.00 & - \\
\hline Brood size at fledging & 11 & 0.24 & 0.16 & 0.24 & 0.01 & 0.35 & - & 0.72 & 1.51 & 0.75 & 7.33 & 0.00 & - \\
\hline Foraging trip duration & 11 & 0.27 & 0.36 & - & - & - & 0.37 & 0.66 & 0.07 & - & - & - & 0.00 \\
\hline Laying success & 15 & 0.53 & 0.26 & 0.14 & 0.01 & 0.07 & - & 0.00 & 1.46 & 2.71 & 8.93 & 4.09 & - \\
\hline Hatching success & 14 & 0.52 & 0.10 & 0.20 & 0.01 & 0.16 & - & 0.00 & 3.26 & 1.87 & 7.28 & 2.40 & - \\
\hline Chick feeding rate & 10 & 0.46 & 0.23 & 0.26 & 0.00 & 0.05 & - & 0.00 & 1.40 & 1.16 & 13.31 & 4.61 & - \\
\hline Density at sea & 12 & 0.00 & 0.25 & 0.36 & 0.10 & 0.28 & - & 11.72 & 0.72 & 0.00 & 2.49 & 0.50 & - \\
\hline Fledging success & 13 & 0.00 & 0.00 & 0.00 & 0.06 & 0.94 & - & 13.63 & 15.52 & 14.55 & 5.57 & 0.00 & - \\
\hline Breeding success & 15 & 0.02 & 0.01 & 0.01 & 0.09 & 0.88 & - & 7.72 & 10.04 & 8.48 & 4.67 & 0.00 & - \\
\hline \multicolumn{14}{|l|}{ Common murre $U$. aalge } \\
\hline Adult body condition & 13 & 0.72 & 0.13 & 0.13 & 0.00 & 0.02 & - & 0.00 & 3.38 & 3.39 & 12.95 & 7.32 & - \\
\hline Fledgling body condition & 10 & 0.06 & 0.01 & 0.07 & 0.01 & 0.85 & - & 5.31 & 8.50 & 5.09 & 9.03 & 0.00 & - \\
\hline Chick feeding rate & 15 & 0.38 & 0.22 & 0.23 & 0.02 & 0.15 & - & 0.00 & 1.07 & 1.00 & 6.46 & 1.79 & - \\
\hline Hatching success & 14 & 0.30 & 0.19 & 0.13 & 0.03 & 0.36 & - & 0.36 & 1.29 & 2.06 & 5.27 & 0.00 & - \\
\hline Foraging trip duration & 15 & 0.05 & 0.45 & - & - & - & 0.51 & 4.82 & 0.25 & - & - & - & 0.00 \\
\hline Fledging success & 13 & 0.71 & 0.13 & 0.13 & 0.00 & 0.03 & - & 0.00 & 3.34 & 3.47 & 11.95 & 6.32 & - \\
\hline Breeding success & 14 & 0.63 & 0.13 & 0.14 & 0.00 & 0.10 & - & 0.00 & 3.14 & 3.00 & 12.07 & 3.74 & - \\
\hline Attendance at incubation & 14 & 0.13 & 0.05 & 0.18 & 0.05 & 0.59 & - & 3.01 & 4.86 & 2.36 & 4.99 & 0.00 & - \\
\hline Attendance at chick-rearing & 15 & 0.00 & 0.14 & 0.70 & 0.08 & 0.08 & - & 11.48 & 3.24 & 0.00 & 4.35 & 4.25 & - \\
\hline Density at sea & 12 & 0.01 & 0.14 & 0.27 & 0.06 & 0.52 & - & 7.41 & 2.70 & 1.33 & 4.40 & 0.00 & - \\
\hline
\end{tabular}

density (i.e. Arctic skua Stercorarius parasiticus, Furness \& Camphyusen 1997; Arctic tern Sterna paradisaea, Suddaby \& Ratcliffe 1997; and black-browed albatross Thalassarche melanophris, Reid et al. 2005), and the aggregative response of common murres Uria aalge and Atlantic puffins Fratercula arctica to prey schools at sea is sigmoidal (Piatt 1990).

We did not exhaust the list of possible seabird parameters that could be examined (e.g. survival), and we might not have been able to resolve relationships in some parameters, owing in part to small sample sizes and inter-colony sources of variability that were not accounted for in our study (Harding et al. 2007). It is also noteworthy that some parameters were independent of prey density over a wide range of poor to excellent feeding conditions, and this is discussed in more detail below (see 'Poor indicators').

The fact that many of these functional relationships were non-linear demonstrates that, like other vertebrate predators (Murdoch \& Oaten 1975), seabirds are constrained by basic physical (e.g. prey dispersion) and biological (e.g. prey quality, assimilation) factors in how efficiently they can exploit local prey resources (Piatt 1990). Constraints may operate at each end of the prey-density spectrum, leading to suppression of a response at low prey densities or a plateau in response at high prey densities (Holling 1959). Whatever the ecological explanation, non-linearity has practical implications for using seabirds as indicators of prey stocks. Indicators are most useful if they have sensitive and predictable relationships with the environmental feature we wish to monitor over the full, continuous range of environmental variation likely to be encountered (Dale \& Beyeler 2001). Unfortunately, our study suggests that few seabird parameters are correlated in a continuous fashion to changes in prey or, at best, they are linearly related over a small range of prey densities.

\section{Different parameter thresholds}

Therefore, we are often left with interpreting nonlinear seabird responses, which tend to fluctuate rapidly between low and high values over relatively small ranges of prey density. This is still useful, but obviously more limiting. It is also why Cairns proposed using a suite of concurrently measured parameters to assess changes in prey stocks. In order for this to work, however, Cairns' second prediction would need to be true: that different seabird parameters would have differing thresholds to prey density (Fig. 1). 
Black-legged kittiwake
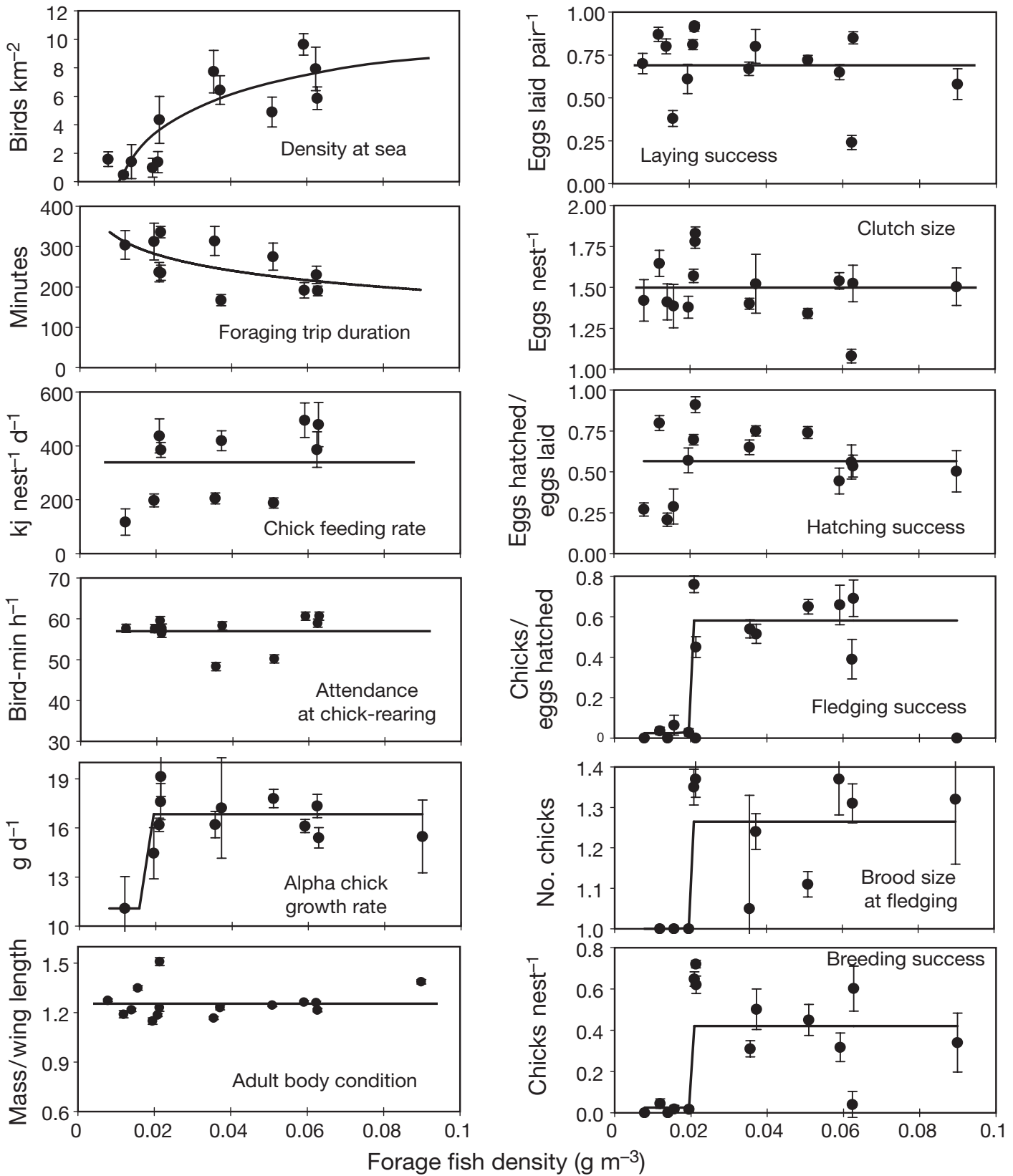

Fig. 4. Rissa tridactyla. Response of different parameters of kittiwake biology or behavior to variation in prey density. Graphs include predicted form (solid line) of relationship from the best-fitting model function (null, linear, hyperbolic, sigmoidal, step, or exponential decay) as determined by using Akaike's information criterion adjusted for sample size $\left(\mathrm{AIC}_{\mathrm{c}}\right)$ analysis

Our results did not provide strong support for this prediction. Mid-point thresholds (inflection points) in our sigmoidal and step response curves (Table 1) were very similar, occupying a narrow range of prey densities $\left(0.018\right.$ to $\left.0.021 \mathrm{~g} \mathrm{~m}^{-3}\right)$ within the range $(0.008$ to $0.090 \mathrm{~g} \mathrm{~m}^{-3}$ ) observed during 15 colony-years of acoustic surveys. However, we did observe higher mid-points (e.g. $0.028 \mathrm{~g} \mathrm{~m}^{-3}$ ) in foraging-trip durations of murres Uria aalge and kittiwakes Rissa tridactyla.
This is consistent with Cairns' prediction that activity budgets would change at higher prey densities in order to buffer foraging success. This was the only parameter type with significantly higher thresholds, but also the only parameter with a threshold measured as the $50 \%$ mid-point (in contrast to inflection point).

Aside from this possible exception, why should prey density thresholds for other foraging activities, attendance, chick growth, and breeding success all be the 

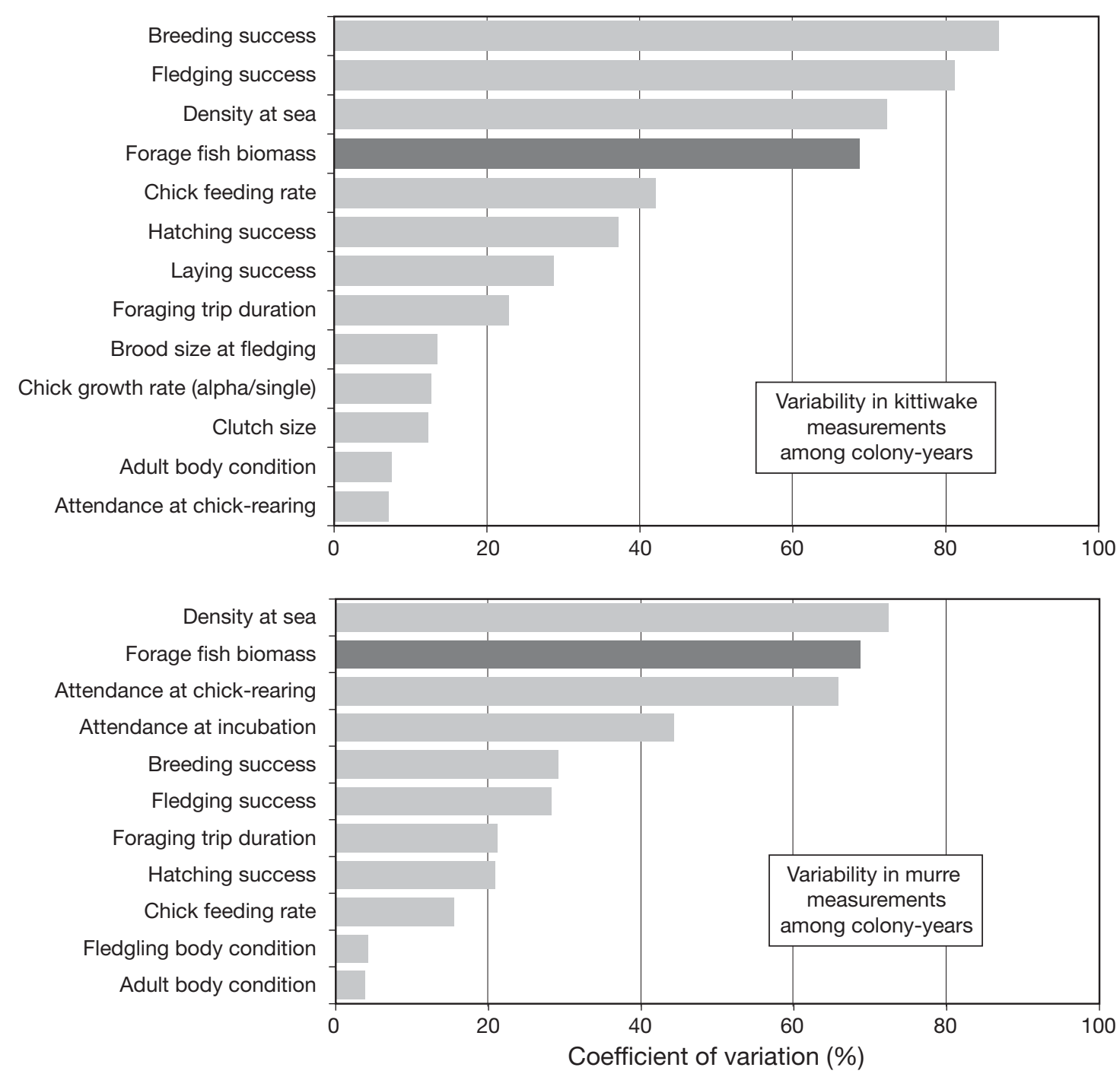

Fig. 5. Rissa tridactyla, Uria aalge. A comparison of variability among colony-years in different parameters of kittiwake and murre biology and behavior, with respect to variability in the food supply (darker bar)

same? Perhaps because there is only one true physical threshold, and that is the fish school density above which seabirds can successfully acquire food energy at a rate that is sufficient to support daily metabolic demands (Piatt 1990). Tracking of prey at sea (aggregative response) sets the baseline variability for all other parameters, because success in prey acquisition (which dictates foraging-trip duration and timeactivity budget) depends on success in tracking the prey, and, in turn, all other parameters (chick-feeding rate, chick growth, reproductive success) vary with the rate of prey acquisition and subsequent rate of energy delivery (e.g. Jodice et al. 2006). In contrast to Cairns' prediction, then, we conclude that most response parameters should have the same threshold, rather than a wide range of thresholds, to prey density.
On the other hand, murres can buffer breeding success against declining prey densities by re-directing discretionary colony attendance time towards foraging (Burger \& Piatt 1990, Zador \& Piatt 1999). Consequently, we observed little or no response in murre breeding success, while attendance time-budgets varied with prey density in non-linear fashion (Harding et al. 2007). In this case, Cairns' prediction was probably correct: a failure in murre breeding success would indicate much lower food supplies than a failure or decline in any other parameter we measured, or at least point to some unusual changes in the environment. For example, recent unusual breeding failures of murres in the North Sea were attributed not to scarcity of prey, but to unusually low (and unexplained) energy value of prey (Wanless et al. 2005). 


\section{Differential species responses}

We found strong support for Cairns' prediction that different species would respond differently to fluctuations in food supply. In the most extreme example, kittiwake breeding success was strongly influenced by food supply (Table 1) and slightly more variable (Fig. 5), whereas murre breeding success was independent of food supply in our study and less than half as variable. One explanation for this difference is that murres have little difficulty meeting their nutritional needs over a wide range of prey availabilities, and when they do, they simply reallocate some discretionary time to foraging effort in order to buffer their reproductive success (Harding et al. 2007). In contrast, kittiwakes are near their maximum performance limits most of the time and have little or no discretionary time to buffer against a reduction in prey availability.

Consider the differences in morphology, life history, and foraging behavior that account for this differential response. Murres must acquire more food than kittiwakes to sustain themselves each day because of differences in body size (1040 vs. $405 \mathrm{~g}$, respectively, in Cook Inlet), costs of flight (wing loading: 1.86 vs. $0.39 \mathrm{~g}$ $\mathrm{cm}^{-2}$; Gabrielsen 1994), and foraging (diving vs. surface-feeding). We calculate from measures of field metabolic rates (FMR; Gabrielsen 1994) and assimilation efficiency ( $87 \%$; Romano et al. 2006) that murres (2.14 kJ d ${ }^{-1} \mathrm{~g}^{-1}$ FMR) and kittwakes $\left(2.03 \mathrm{~kJ} \mathrm{~d}^{-1} \mathrm{~g}^{-1}\right.$ FMR) feeding on sand lance $\left(5.0 \mathrm{~kJ} \mathrm{~g}^{-1}\right.$ wet; Van Pelt et al. 1997) would need to capture and eat 512 and $189 \mathrm{~g}$, respectively, of fish per day. This is actually a similar burden for each species because it represents about half their respective body masses.

From this point forward, however, additional daily needs may diverge markedly between species, owing to costs of rearing and feeding chicks (Gabrielsen 1994). The cost of rearing 1 chick increases demand from 49 to $53 \%$ of body mass in adult murres (an $8 \%$ increase), but from 46 to $67 \%$ of body mass in adult kittiwakes (a $46 \%$ increase). Adult kittiwakes raising 2 chicks need to acquire $381 \mathrm{~g}$ of sand lance daily, or $94 \%$ of their body mass (a $104 \%$ increase in demand). Since murres lay only 1 egg, and raise chicks to only one-quarter adult mass before fledging, they never incur the same obligation as kittiwakes that often try (and more often fail) to raise 2 chicks in Alaska (Hatch et al. 1993).

Furthermore, even though murres need to acquire 1.5 to 2.7 times more prey biomass daily than kittiwakes, they typically acquire what they need in about half the time. On average, kittiwake foraging trips were about $1.4 \mathrm{~h}$ longer than those of murres (typically $2 \mathrm{~h}$ ) in Cook Inlet, a difference also observed elsewhere (Hamer et al. 1993, Monaghan et al. 1994).
Because murre and kittiwake chicks need about 4 meals per day, the cumulative result is an enormous difference in foraging time-budgets between species. It explains why murres have several hours of extra discretionary time to reallocate to foraging when prey are scarce, while kittiwakes have almost none. The difference may arise from the fact that kittiwakes are restricted to feeding only on organisms found at the sea surface $(<0.5 \mathrm{~m})$, whereas murres can dive deep enough to exploit the entire water column of lower Cook Inlet. If most of the exploitable fish biomass is above $50 \mathrm{~m}$ (Speckman 2004), murres would have access to 100 times more prey biomass than kittiwakes at any given distance from a colony.

In summary, every species of seabird has a different set of biological and behavioral adaptations for responding to changes in food supply, so we do not expect all species to react the same way. A further point made by Cairns (1987) and corroborated in our study is that if we wish to use multiple seabird species as indicators of marine food supplies, we had better first characterize the similarities and differences in their response to variability in food supply. Additionally, it may be useful to combine response data from different species using a multivariate index that captures the essence of the response and allows us to use a selection of species as multivariate indicators of food supplies (Reid et al. 2005, Fredericksen et al. 2006, Piatt \& Harding 2007).

\section{Poor indicators}

It is equally important and biologically interesting to consider which parameters are not useful indicators of marine food supplies. The list of parameters that we studied is by no means exhaustive, but did include some that are often listed among useful indicators (Cairns 1987, Weimerskirch et al. 2001, Reid et al. 2005). In particular, this includes body condition and clutch size.

We found no relationship between adult body condition and food density for either murres or kittiwakes. These results were not expected. It was reasonable to assume that body condition would be sensitive to variations in food supply (Monaghan et al. 1989, Hamer et al. 1991). Experimental studies have shown that adult body condition can be affected negatively by increasing workload (Golet \& Irons 1999). In field studies where seasonal variability in body mass was accounted for in the analysis, however, variability in adult body condition among years was exceedingly low ( $\mathrm{CV}=0.6$ to $6.6 \%$ ) for skua, terns, albatross, murres, and kittiwakes (Harris \& Wanless 1988, Hamer et al. 1991, Suddaby \& Ratcliffe 1997, Weimerskirch et al. 
2001). Reid et al. (2005) examined annual variability in 32 parameters of seabird and mammal biology in the Antarctic, and found that the 7 least variable parameters involved measures of body mass (e.g. birth mass, fledging mass, adult arrival mass, etc.) and all had CVs $<10 \%$.

This suggests that both murres and kittiwakes minimize variability in their own body condition. This is consistent with the idea of a trade-off between investment in the current year's reproductive effort and subsequent adult survival (Stearns 1992). The importance of maintaining adult body condition is implied from the strong linkage between body condition and survival in seabirds (Erikstad et al. 1998, Golet et al. 1998, Weimerskirch et al. 2001). After taking care of themselves, it follows that adults would try to minimize variation in chick growth and condition, which is linked with survival to breeding age (Sagar \& Horning 1998, Weimerskirch et al. 2000).

Black-legged kittiwakes lay up to 3 eggs per clutch, but clutch size and laying success in kittiwakes were independent of food supply in Cook Inlet. On average, $69 \%$ of pairs that attempted to breed eventually laid eggs. For those that laid, the average clutch size was $1.49 \pm 0.18 \mathrm{SD}$ eggs per nest. Laying success $(\mathrm{CV}=$ $29 \%)$ was more variable than clutch size $(\mathrm{CV}=12 \%)$. These observations may be explained in at least 2 ways. First, there was a gap in time between measurements: clutch size and laying success were measured in June, while food supply was measured in late July to early August. Alternatively, kittiwakes may have a programmed approach to egg-laying that is largely independent of food supply except under extreme conditions, i.e. when food supplies and nutrient reserves are so low as to preclude egg formation. Evidence from a variety of seabirds suggests that clutch size is usually maximized and regulation of breeding effort occurs later, by brood reduction or nest desertion (e.g. Monaghan et al. 1989, Sydeman et al. 1991, Hamer et al. 1993, Suddaby \& Ratcliffe 1997).

\section{Conclusions and future considerations}

We join the ranks of those who promote the cautious use of seabirds as indicators of marine food supplies and call for more studies to elucidate the form of functional relationships and sources of variability (Cairns 1987, Montevecchi 1993, Furness \& Camphuysen 1997, Reid et al. 2005). However, it is now clear that we ought not to expect many linear relationships between parameters of seabird biology and food supply (Reid et al. 2005). Seabirds are in most circumstances unlikely to gauge subtle or continuous changes, but they may perform well as binary indicators (Montevecchi 2007, this Theme Section) that signal changes from good to bad, and vice versa. On the other hand, foraging-trip duration was one parameter that varied continuously (if not linearly) with prey density, and is perhaps deserving of more attention.

While other factors such as weather and predation can influence kittiwake breeding success (Hamer et al. 1993, Hatch et al. 1993), the species appears to be very sensitive to fluctuations in food supply. This parameter should, therefore, prove to be a reliable long-term indicator of variability in the marine environment (e.g. Aebischer et al. 1990, Piatt \& Harding 2007). In contrast, murre breeding success may tell us little about food supplies, except under extreme circumstances, whereas murre time-budgets are sensitive to prey fluctuations. Given that murre species are widely being monitored in the Northern Hemisphere (Gaston \& Jones 1998), it is perhaps time to add attendance timebudgets to the repertoire of parameters we routinely measure at murre colonies.

It is useful to know the form of a seabird's response to changing prey density, but the variability of its response is equally important in assessing its ability to deal with change. We find it intriguing that independent studies of seabirds in Alaska (Fig. 5) and the Antarctic (penguin and albatross; Reid et al. 2005), with similar sampling effort, found that (1) the highest CV of any parameter was $<90 \%$ in both studies and (2) that some parameters in both studies fell into similar groupings of those with low CVs (e.g. body condition), moderate CVs (e.g. foraging), and high CVs (e.g. breeding success). This leads us to wonder: are there limits in variability, and do these differ much among species and ecosystems? To what extremes of variation can seabirds be pushed by climate change and regime shifts (e.g. Sydeman et al. 1991, Anderson \& Piatt 1999) before they collapse? If there are differences among species, can we predict which species will be the best indicators of unusual variability in their environments?

Finally, we note that despite many advances in knowledge since Cairns' predictions were made, much uncertainty remains about using seabirds as indicators of marine food supplies (Fredericksen et al. 2006). More research is needed on a wider variety of seabird species and their functional relationships with prey. Also, we think that for some parameters, responses may not be evident except under the most extreme conditions of prey scarcity. It may be that experimental situations (e.g. with captive birds in aquaria, manipulative experiments in the wild) are needed to address this gap. In general, some of the best indicators in our study (and Reid et al. 2005) were those which had both high annual variability and a strong functional relationship with prey density. Paradoxically, highly variable parameters are not recommended for use as eco- 
logical indicators (Dale \& Beyeler 2001). Less variable parameters might be just as sensitive, but less practical if they have a weaker signal-to-noise ratio. Owing to these many uncertainties, and until we better understand the responses of individual species, it may be most prudent to combine data from multiple parameters and species to generate robust multivariate indicators of prey stocks (Fredericksen et al. 2006, Piatt \& Harding 2007). In any case, we find it encouraging that increasing evidence points to bottom-up control of seabird populations (Aebischer et al. 1990, Speckman et al. 2005, Fredericksen et al. 2006), which further suggests that seabirds are likely to track spatial and temporal variation in prey abundance.

Acknowledgements. We thank A. Abookire, A. Benson, J. Albertson, C. Alley, M. Arimitsu, J. Benson, D. Black, M. Blanding, G. Brady, J. Bussler, L. Ochikubo [Chan], A. Chapman, M. Eaton, J. Figurski, M. Gray, J. Hammer, G. Hoffman, J. Hoover, B. Keitt, R. Kitaysky, J. Maletta, R. Papish, M. Post, M. Robards, M. Schultz, B. Smith, E. Sommer, B. Stahl, T. Steeves, M. Wada, S. Wang, J. Wetzel, L. Wilensky, S. Wright, C. Wrobel, S. Zador, and S. Zuniga for tireless efforts in the field. We thank G. Snedgen, B. Keitt, the staff of Kasitsna Bay Marine Lab, residents of Chisik Island, Tuxedni Channel, Halibut Cove, and Kasitsna Bay for their support. Funding and logistic support were provided by the Alaska Science Center (USGS), the Alaska Maritime National Wildlife Refuge (USFWS), and the Exxon Valdez Oil Spill Trustee Council (APEX Restoration Projects 96163M and 96163J). We are grateful to K. Bixler, K. Oakley, B. Sydeman and 3 anonymous reviewers for helpful comments on previous drafts of this paper.

\section{LITERATURE CITED}

Abookire AA, Piatt JF (2005) Oceanographic conditions structure forage fishes into lipid-rich and lipid-poor communities in lower Cook Inlet, Alaska, USA. Mar Ecol Prog Ser 287:229-240

Aebischer NJ, Coulson JC, Colebrook JM (1990) Parallel long-term trends across four marine trophic levels and weather. Nature 347:753-755

Anderson PJ, Piatt JF (1999) Community reorganization in the Gulf of Alaska following ocean climate regime shift. Mar Ecol Prog Ser 189:117-123

Benson J, Suryan RM, Piatt JF (2003) Assessing chick growth from a single visit to a seabird colony. Mar Ornithol 31: 181-184

Brooke ML (2004) The food consumption of the world's seabirds. Proc R Soc Lond (Suppl)271:246-248

Burger AE, Piatt JF (1990) Flexible time budgets in breeding common murres: buffers against variable prey availability. Stud Avian Biol 14:71-83

Burnham KP, Anderson DR (2002) Model selection and multimodel inference: a practical information-theoretic approach. Springer-Verlag, New York

Cairns DK (1987) Seabirds as indicators of marine food supplies. Biol Oceanogr 5:261-271

Dale VH, Beyeler SC (2001) Challenges in the development and use of ecological indicators. Ecol Indic 1:3-10

Erikstad KE, Fauchald P, Tveraa T, Steen H (1998) On the cost of reproduction in long-lived birds; the influence of environmental variability. Ecology 79:1781-1788

Frederiksen M, Edwards M, Richardson AJ, Halliday NC, Wanless S (2006) From plankton to top predators: bottomup control of a marine food web across four trophic levels. J Anim Ecol 75:1259-1268

Furness RW, Camphuysen CJ (1997) Seabirds as monitors of the marine environment. ICES J Mar Sci 54:726-737

Gabrielsen GW (1994) Energy expenditure in Arctic seabirds. $\mathrm{PhD}$ thesis, University of Tromso

Gaston AJ, Jones IL (1998) The auks. Oxford University Press, Oxford

Golet GH, Irons DB (1999) Raising young reduces body condition and fat stores in black-legged kittiwakes. Oecologia 120:530-538

Golet GH, Irons DB, Estes JA (1998) Survival costs of chick rearing in black-legged kittiwakes. J Anim Ecol 67: 827-841

Gould PJ, Forsell DJ (1989) Techniques for shipboard surveys of marine birds. Fish and Wildlife technical report 25, US Dept. of Interior, Fish and Wildlife Service, Washington, DC

Hamer KC, Furness RW, Caldow RWG (1991) The effects of changes in food availability on the breeding ecology of great skuas Catharacta skua in Shetland. J Zool Lond 223: 175-188

Hamer KC, Monaghan P, Uttley JD, Walton P, Burns MD (1993) The influence of food supply on the breeding ecology of kittiwakes Rissa tridactyla in Shetland. Ibis 135: $255-263$

Harding AMA, van Pelt TI, Piatt JF, Kitaysky AS (2002) Reduction of provisioning effort in response to experimental manipulation of chick nutritional status in the horned puffin Fratercula corniculata. Condor 104:842-847

Harding AMA, Piatt JF, Schmutz JA, Shultz MT, van Pelt TI, Kettle AB, Speckman SG (2007) Prey density and the behavioral flexibility of a marine predator: the common murre (Uria aalge). Ecology 88:2024-2033

Harris MP, Wanless S (1988) The breeding biology of guillemots Uria aalge on the Isle of May over a six year period. Ibis 130:172-192

Hatch SA, Byrd GV, Irons DB, Hunt GL (1993) Status and ecology of kittiwakes (Rissa tridactyla and R. brevirostris) in the North Pacific. In: Vermeer K, Briggs KT, Morgan $\mathrm{KH}$, Siegel-Causey D (eds) The status, ecology, and conservation of marine birds of the North Pacific. Special Publication, Canadian Wildlife Service, Ottawa, p 140-153

Holling CS (1959) The components of predation as revealed by a study of small mammal predation of the European pine sawfly. Can Entomol 91:293-320

Jodice PGR, Roby DD, Turco KR, Suryan RM and others (2006) Assessing the nutritional stress hypothesis: relative influence of diet quantity and quality on seabird productivity. Mar Ecol Prog Ser 325:267-279

Kitaysky AS, Wingfield JC, Piatt JF (1999) Dynamics of food availability, body condition and physiological stress response in breeding black-legged kittiwakes. Funct Ecol 13:577-584

Monaghan P, Uttley JD, Burns M, Thane C, Blackwood J (1989) The relationship between food supply, reproductive effort, and breeding success in Arctic terns Sterna paradisea. J Anim Ecol 58:261-274

Monaghan P, Walton P, Wanless S, Uttley JD, Burns MD (1994) Effects of prey abundance on the foraging behaviour, diving efficiency and time allocation of breeding guillemots Uria aalge. Ibis 136:214-222

Montevecchi WA (1993) Birds as indicators of change in marine prey stocks. In: Furness RW, Greenwood DJ (eds) 
Birds as monitors of environmental change. Chapman \& Hall, London, p 217-266

Montevecchi WA (2007) Binary dietary responses of northern gannets Sula bassana indicate changing food web and oceanographic conditions. Mar Ecol Prog Ser 352:213-220

Murdoch WW, Oaten A (1975) Predation and population stability. Adv Ecol Res 9:1-131

Piatt JF (1990) Aggregative response of common murres and Atlantic puffins to their prey. Stud Avian Biol 14:36-51

Piatt JF, Harding AMA (2007) Population ecology of seabirds in Cook Inlet. In: Spies R (ed) Long-term ecological change in the northern Gulf of Alaska. Elsevier, Amsterdam, p 335-352

Piatt JF, Methven DA (1992) Threshold foraging behavior of baleen whales. Mar Ecol Prog Ser 84:205-210

Reid K, Croxall JP, Briggs DR, Murphy EJ (2005) Antarctic ecosystem monitoring: quantifying the response of ecosystem indicators to variability in Antarctic krill. ICES J Mar Sci 62:366-373

Robards MD, Piatt JF, Kettle AB, Abookire AA (1999) Temporal and geographic variation in fish communities of lower Cook Inlet, Alaska. Fish Bull 97:962-977

Romano MD, Piatt JF, Roby DD (2006) Testing the junk-food hypothesis on marine birds: effects of prey type on growth and development. Waterbirds 29:407-516

Sagar P, Horning DS (1998) Mass related survival of fledging sooty shearwaters Puffinus griseus at the Snares, New Zealand. Ibis 140:329-339

Speckman SG (2004) Characterizing fish schools in relation to the marine environment and their use by seabirds in lower Cook Inlet, Alaska. PhD thesis, University of Washington, Seattle, WA

Speckman S, Piatt JF, Minte-Vera C, Parrish J (2005) Parallel structure among environmental gradients and three trophic levels in a subarctic estuary. Prog Oceanogr 66:25-65

Editorial responsibility: Howard Browman (Associate Editorin-Chief), Storebø, Norway
Stearns SS (1992) The evolution of life histories. Oxford University Press, New York

Suddaby D, Ratcliffe D (1997) The effects of fluctuating food availability on breeding Arctic terns (Sterna paradisaea). Auk 114:524-530

Suryan RM, Irons DB (2001) Colony and population dynamics of black-legged kittiwakes in a heterogeneous environment. Auk 118:636-649

Sydeman WJ, Hester MM, Thayer JA, Gress F, Martin P, Buffa J (2001) Climate change, reproductive performance and diet composition of marine birds in the southern California Current System, 1969-1997. Prog Oceanogr 49: 309-329

Uttley JD, Walton P, Monaghan P, Austin G (1994) The effects of food abundance on breeding performance and adult time budgets of guillemots Uria aalge. Ibis 136: 205-213

Van Pelt TI, Piatt JF, Lance BK, Roby DD (1997) Proximate composition and energy density of some North Pacific forage fishes. Comp Biochem Physiol A 118A:1393-1398

Wanless S, Harris MP, Redman P, Speakman JR (2005) Low energy values of fish as a probable cause of a major seabird breeding failure in the North Sea. Mar Ecol Prog Ser 294:1-8

Weimerskirch H, Prince PA, Zimmermann L (2000) Chick provisioning by the yellow-nosed albatross: response of foraging effort to experimentally increased costs and demands. Ibis 142:103-110

Weimerskirch H, Zimmermann L, Prince PA (2001) Influence of environmental variability on breeding effort in a longlived seabird, the yellow-nosed albatross. Behav Ecol 12: 22-30

Zador S, Piatt JF (1999) Time-budgets of common murres at a declining and increasing colony in Alaska. Condor 101: 149-152

Submitted: October 26, 2006; Accepted: July 27, 2007

Proofs received from author(s): October 23, 2007 